RETRACTION NOTE

Masanori Sugisaka

\title{
Erratum to: Dense stereovision using mono-CCD color cameras
}

Erratum to: Artif Life Robotics (2010) 15:508-511 DOI 10.1007/s10015-010-0853-0

The editors of the journal Artificial Life and Robotics hereby retract the article "Dense stereovision using monoCCD color cameras" by Hachem Halawana, Hani Hamdan, and Mohamad Hamdan, which appeared in Artif Life Robotics (2010) 15:508-511.

The article is being retracted because it contained the same research data used in the chapter titled "Color Stereo Matching Cost Applied to CFA Images" by Hachem Halawana, Ludovic Macaire, and François Cabestaing, published in Computational Color Imaging Second International
Workshop, CCIW 2009, Saint-Etienne, France, March 26-27, 2009. Revised Selected Papers, edited by A. Trémeau, R. Schettini, and S. Tominaga (LNCS 5646, pp. 170-179, 2009.(C) Springer-Verlag Berlin Heidelberg 2009).

Duplicate or redundant publication is a serious violation of scientific practice and is damaging to a journal or other publication. Please be reminded that it is an author's absolute responsibility to strictly comply with rigorous scientific and professional standards when submitting a manuscript for publication. 